\title{
Alcohol sale status and homicide victimization in Kentucky, 2005-2012: Is there a spatial association?
}

\author{
Hanan Abdulghafoor Khaleel, ${ }^{1}$ Sabrina Brown, ${ }^{2}$ Steven Fleming, ${ }^{2}$ W. Jay Christian ${ }^{2}$ \\ ${ }^{1}$ Surveillance Section, Communicable Diseases Control Center, Directorate of Public Health, Ministry of \\ Health, Baghdad, Iraq; ${ }^{2}$ Department of Epidemiology, College of Public Health, University of Kentucky, \\ Lexington, KY, USA
}

\begin{abstract}
To date, the association between the alcohol sale status of decedents' residence and alcohol-related homicide victimization have not been studied as far as we know. The current study aims to: i) determine whether homicide victims who were residents of wet counties had higher odds of testing positive for alcohol than their counterparts in moist or $d r y$ counties after adjusting for confounders; ii) determine whether homicides and alcohol-related homicides tend to cluster spatially; iii) determine whether the aforementioned associations exist only in highly-populated counties. A multilevel logistic regression analysis was used to analyze the data on homicide victims in the Kentucky Violent Death Reporting System from 2005 to 2012 . Spatial statistics were used to determine the spatial autocorrelation in rates of homicides and alcohol-related homicides. Overall, 944 homicide victims were included. The male to female ratio was $3: 1$. About $32.8 \%$ of homicide victims tested positive for alcohol. About $33.0 \%$ of homicide decedents who were residents in wet counties tested positive for alcohol compared to
\end{abstract}

Correspondence: Hanan Abdulghafoor Khaleel, Surveillance Section, Communicable Diseases Control Center, Directorate of Public Health, Ministry of Health, Baghdad, Iraq.

Tel.: +9647901472335.

E-mail: hanan_azawy2000@yahoo.com

Key words: Homicide; Alcohol; Sale status; USA.

Contributions:HAK: design and analysis, writing of the manuscript; SB: providing data, reviewing and editing the manuscript; SF: reviewing and editing the manuscript; WJC: reviewing the spatial analysis and mapping.

Conflict of interest: the authors declare no potential conflict of interest.

Funding: none.

Received for publication: 25 October 2018.

Revision received: 12 February 2019.

Accepted for publication: 19 February 2019.

(C) Copyright H.A. Khaleel et al., 2019

Licensee PAGEPress, Italy

Geospatial Health 2019; 14:747

doi:10.4081/gh.2019.747

This article is distributed under the terms of the Creative Commons Attribution Noncommercial License (CC BY-NC 4.0) which permits any noncommercial use, distribution, and reproduction in any medium, provided the original author(s) and source are credited.
$32.5 \%$ of their counterparts in moist/dry counties. Residence in wet counties was associated with a statistically insignificant increase in the unadjusted odds ratio (OR) of alcohol-related homicide victimization $(\mathrm{OR}=1.20,95 \% \mathrm{CI}=0.81-1.77)$ as well as the adjusted odds $(\mathrm{aOR}=1.33,95 \% \mathrm{CI}=0.83-2.12)$. There was no association between population size and alcohol-related homicide rate.

\section{Introduction}

Homicide is among the top ten leading causes of death in adults in the United States (Logan et al., 2011; Centers for Disease Control and Prevention, 2014) and alcohol consumption together with homicide victimization is a major public health problem (Grucza et al., 2012). Prior studies of homicide victimization and alcohol show that alcohol was present in about $50 \%$ of homicide victims (Darke, 2010; Kuhns and Maguire, 2012). Among the various causes of violent deaths that occurred In the state of Kentucky between 2005 and 2010 (Walsh et al., 2009), homicide was the second most common (22\%). Several countries have implemented policies limiting alcohol use to reduce alcohol-related harms, such as suicide, homicide, other violent crimes and vehicle accidents. Such policies included banning alcohol sales, limiting number of alcohol outlets (Branas et al., 2011; Parker et al., 2011; Jennings et al., 2014; Giesbrecht et al., 2015), applying high alcohol taxes (Zeoli and Webster, 2010), limiting hours of alcohol sales (Duailibi et al., 2007; Malaga et al., 2012), limiting days of alcohol sales (Middleton et al., 2010; Heaton, 2012), setting a maximum blood alcohol level when driving (Grucza et al., 2012) and limiting age when drinking is allowed (Grucza et al., 2012). Results from studies on the effect of the aforementioned policies on reducing homicide victimization are conflicting. For example, one of the earliest policies restricting alcohol in the United States is the constitutional prohibition of alcohol in 1920 (Asbridge and Weerasinghe, 2009). A study on the effect of the enactment of this policy employed an interrupted time series of 11,018 homicide victims and offenders in Chicago between 1870 and 1930 found no change in the alcohol-related homicide rates, a $21 \%$ increase in total homicides and an $11 \%$ increase in the nonalcohol-related homicides (Asbridge and Weerasinghe, 2009). They attributed the absence of change in alcohol-related homicide rates to underestimation, or possibly that the prohibition was not sufficiently enforced to effectively stop people from drinking. The rise in total and non-alcohol-related homicides was explained by a possible black market, organized crime and the existence of a subculture of violence at that time (Asbridge and Weerasinghe, 2009). Several questions remain unanswered in that study due to lack of data. For example, did the prohibition impact the economy by increasing the unemployment rate and poverty lead to violence? Alternatively, was the prohibition associated with the emergence of other substance- 
abuse activities leading to violence? On the other hand, a prior study of alcohol availability and homicides found that an increase in alcohol sales was associated with an increase of homicides rates in men only, which suggests that both alcohol and violence are more common in men (Ray et al., 2008). Similarly, another study of the association between the number of on-premise violent crimes in Kansas showed that a $10 \%$ increase in drinking establishments was associated with a $3.7 \%$ to $4.1 \%$ increase in violent crime suggesting that alcohol might act as a catalyst for violent behaviours (Anderson et al., 2014). A major limitation of the prior studies is the ecologic fallacy, which means that results cannot be generalized to individuals.

Kentucky has diverse and continuously changing alcohol laws that result in an intermingled combination of wet counties (32), moist (49) and dry ones (39). Dry counties are counties that prohibit all sale of alcoholic beverages, wet counties those that permit full retail sales of alcohol under state license whereas moist counties are those with a wet city in a dry county or which only allow sale of alcohol at select sites, such as historic sites. The classification is not strict and moist cities can be in dry counties and vice versa (Department of Alcoholic Beverage Control, 2015). To date, there is no study of the association between the alcohol sale status of decedents' residence and homicide victims testing positive for alcohol in Kentucky. In this study, we used the term alcohol-related homicide to refer to victims testing positive for alcohol, not perpetrators. The current study aims to determine: i) whether homicide victims who are residents of wet counties have higher odds of testing positive for alcohol post mortem than homicide victims who are residents of moist/dry counties, after adjusting for confounding factors; ii) whether there is spatial autocorrelation among homicide and/or alcohol-related homicide rates in wet counties; and iii) whether the association between alcohol sale status of a decedents' residence and being an alcohol-related homicide victim exists primarily in counties with high populations.

\section{Materials and Methods}

\section{Data source}

Data on violent deaths for the period 2005 to 2012 were extracted from the Kentucky Violent Death Reporting System (KVDRS), a passive surveillance system that provides a detailed account of violent deaths that have occurred in Kentucky since 2005. The KVDRS combines data from death certificates, coroner/medical examiner reports, police reports, crime laboratory reports and toxicology reports. More information about KVDRS and how it collects data can be found in our previous work (Khaleel et al., 2016). We identified homicide decedents from the KVDRS by the final way of death assigned by the data abstractors.

\section{The exposure variable}

The primary exposure variable was the alcohol sale status of the county in which homicide victims lived. For the purpose of this study, this variable was coded as a binary variable (wet vs moist/dry). Decedent's county of residence was abstracted from the KVDRS and matched to the wet, moist, dry county list released by the Department of Alcoholic Beverage Control in 2015; earlier versions of the list were not easily accessible. The classification of Kentucky counties into wet, moist and dry can be found in our previous work (Khaleel et al., 2016). Briefly, counties were considered dry if alcohol sales were prohibited; moist if alcohol sales were limited to certain places, such as historic places and golf courses; and wet if alcohol sales were allowed without limits.

\section{The outcome variable}

The post mortem level of blood alcohol of homicide victims was defined as a binary variable (positive, negative). Homicides were considered alcohol-related if the post mortem blood alcohol content was higher than $0.0 \%$ (Kaplan et al., 2014; Giesbrecht et al., 2015). Those who were not tested or were tested with an undetermined result were excluded from the multilevel regression analysis; however, they were mapped and examined to determine spatial randomness. If found to be spatially random; no specific spatial pattern was identified.

\section{Confounders and effect modifiers}

Sociodemographic variables included sex (male, female); age group ( $\leq 21,21-30,31-40,41-50,51-60, \geq 61$ years); race (Caucasian, African American/all others/unspecified); and educational level $\left(8^{\text {th }}\right.$ grade, $9-12^{\text {th }}$ grade, high school grade, above high school grade). Other potentially confounding factors, as suggested by the literature, included presence of mental illness (yes, no); substance-abuse problem (yes, no); intimate partner problem (yes, no); argument before homicide (yes, no); marital status (married, never married/single, widowed, divorced/separated); and type of weapon (firearm, poisoning, hanging, sharp objects, all others, unspecified/unknown). However, none of these potential confounders were statistically significant with either the exposure or the outcome and were therefore not included in the final analysis.

Each county's population was classified as either $\leq 35,000$, $35,001-100,000$ or $>100,000$. In addition, Appalachian or nonAppalachian residence of homicide victims was also included as a binary variable. Counties in Appalachia (in the eastern part of Kentucky) were identified using the Appalachian Regional Commission's classification (2015). Further details are mentioned in our previous work (Khaleel et al., 2016). A composite binary variable was created to indicate the presence of substances other than alcohol in the blood. That is, if the post mortem blood was positive for any of the following drugs (amphetamine, antidepressant, benzodiazepines, cocaine, marijuana, anticonvulsants, muscle relaxant, opiate, barbiturates, antipsychotic), the presence of other drugs was considered positive. If the post mortem blood test was negative for all of them, it was considered negative. Although some of these drugs have legitimate medical uses, it was impossible to determine whether this was the case for most homicides.

\section{Statistical analysis}

We used frequencies and percentages in univariate analysis to describe the variables. In the bivariate analysis, the chi square test was used to find possible associations. Factors were considered confounders if they were associated with both exposure and outcome in the bivariate analysis. If their one-sided P-value was less than 0.05 they were included in the fully saturated model. The unadjusted and adjusted odds ratios (ORs) and the $95 \%$ confidence intervals were used to examine the association between alcohol sale status of the area and being an alcohol related homicide victim. To control for the county effects, a multilevel logistic regression model was used to assess which risk factors were significantly associated with being an alcohol-related homicide victim. The final model was adjusted for education level, sex and population. These factors were selected to remain in the final model if they had a P-value less than 0.0001 in 
the fully saturated model for homicides. Testing for interaction by population size was not statistically possible due to limited events related to the confounding factors and was therefore removed from the final model. PROC GLIMMIX (SAS/STAT, 2014), which performs estimation and statistical inference for generalized linear mixed models was used to fit the multilevel logistic regression model with binary distribution, log link function and the residence county as a random intercept. For mapping and spatial analysis, crude rates of homicides in each county were calculated by dividing the total number of homicides by the 2010 population and multiplying by 100,000 . Rates of alcohol-related homicides were calculated by dividing the number of homicide victims who tested positive for alcohol by the total number of the tested decedents and multiplying by 100 . Spatial autocorrelation analysis of the rates of alcohol-related homicides was done using Global Moran's I. Briefly, the value of Global Moran's I varies between -1 and 1. A higher positive Moran's $I$ indicates that similar values tend to cluster together, while a negative value implies that similar values are dispersed. When Moran's $I$ is near 0 , there is no significant spatial clustering or dispersion of values. For this analysis, inverse distance between county centroids was selected as the conceptualization of spatial relationships among counties, implying that neighbouring counties had a larger influence on the computation for a target county than counties that were situated far away. P-values lower than 0.05 were considered statistically significant. A map based on local Moran's I or the local indicators of spatial autocorrelation (LISA) was used to assess whether homicides and alcohol-related homicides were spatially clustered within wet counties. The Local Moran's I was used as an indication whether or not to reject the null hypothesis of no clustering in high or low rates, feature by feature; in effect, whether the apparent similarity (a spatial clustering of either high or low values) or dissimilarity (a spatial outlier) is more pronounced than one would expect in a random dis- tribution. A high positive $\mathrm{z}$-score for a feature indicates that the surrounding features have similar values (either high values displayed as High-High for a statistically significant cluster of high values, or low values given as Low-Low for a statistically significant cluster of low values). A low, negative $\mathrm{z}$-score for a feature indicates a statistically significant spatial data outlier, i.e. a high-value feature surrounded by features with low values (High-Low) or a low value surrounded by high values (Low-High outlier). All statistical tests were one sided with a significance level of 0.05 . All data were analyzed using SAS, version 9.4. Maps, cluster analysis and spatial statistics were done using ArcGIS 10.3 (ESRI, Redlands, CA, USA).

\section{Results}

Table 1 shows that $60.6 \%$ of the 944 homicides that occurred between 2005 and 2012 in Kentucky, occurred in wet counties. A high percentage of homicide victims who were residents of wet counties were less than 30 years old $(48.8 \%)$, black (48.6\%), male $(79.6 \%)$, had a $9^{\text {th }}-12^{\text {th }}$ grade educational attainment $(58.6 \%)$, never married/single (62.2\%) and not residents in Appalachia (93.3\%) (results not shown). Regarding stress-related covariates, a higher percentage of homicide victims in wet counties had an argument before the incident $(26.9 \%)$, had mental health problems $(1.0 \%)$, substanceabuse problems (3.5\%), had other drugs in their blood at the time of the incident $(53.5 \%)$ or died by firearm $(73.8 \%)$. Finally, a high percentage of homicide victims who were residents of wet counties were also residents of counties with populations higher than 100,000 , in contrast to those who were residents of moist/dry counties, where the populations were less than 35,000 residents (data not shown).

Table 2 shows the unadjusted OR, adjusted OR, and 95\% confidence interval for the association between residence in wet coun-

Table 1. Frequency and percentages of homicide victims by decedent's residence alcohol sale status in Kentucky from 2005 to 2012.

\begin{tabular}{|c|c|c|c|c|c|c|c|}
\hline \multirow[b]{2}{*}{ Characteristic } & \multicolumn{2}{|c|}{ Total } & \multicolumn{2}{|c|}{ Wet } & \multicolumn{2}{|c|}{ Moist/Dry } & \multirow[b]{2}{*}{ P-value } \\
\hline & $\begin{array}{c}\mathrm{N} \\
944\end{array}$ & $\begin{array}{c}\% \\
100\end{array}$ & $\begin{array}{c}\mathrm{N} \\
572\end{array}$ & $\begin{array}{c}\% \\
60.6\end{array}$ & $\begin{array}{c}\mathrm{N} \\
372\end{array}$ & $\begin{array}{c}\% \\
39.4\end{array}$ & \\
\hline $\begin{array}{l}\text { Education Level } \\
\text { 8th grade } \\
\text { 9th-12th } \\
\text { High School Grade } \\
\text { Above High School }\end{array}$ & $\begin{array}{c}156 \\
492 \\
209 \\
87\end{array}$ & $\begin{array}{l}16.5 \\
52.1 \\
22.1 \\
9.2\end{array}$ & $\begin{array}{l}68 \\
335 \\
114 \\
55\end{array}$ & $\begin{array}{l}11.9 \\
58.6 \\
19.9 \\
9.6\end{array}$ & $\begin{array}{l}88 \\
157 \\
95 \\
32\end{array}$ & $\begin{array}{l}23.7 \\
42.2 \\
25.5 \\
8.6\end{array}$ & $<0.0001$ \\
\hline $\begin{array}{l}\text { Sex } \\
\text { Male } \\
\text { Female }\end{array}$ & $\begin{array}{l}708 \\
236\end{array}$ & $\begin{array}{l}75.0 \\
25.0\end{array}$ & $\begin{array}{l}455 \\
117 \\
\end{array}$ & $\begin{array}{l}79.6 \\
20.5\end{array}$ & $\begin{array}{l}253 \\
119 \\
\end{array}$ & $\begin{array}{l}68.0 \\
32.0\end{array}$ & $<0.0001$ \\
\hline $\begin{array}{l}\text { Population of residence county } \\
\leq 35,000 \\
35,000-100,000 \\
>100,000\end{array}$ & $\begin{array}{l}316 \\
179 \\
449\end{array}$ & $\begin{array}{l}33.5 \\
19.0 \\
47.6\end{array}$ & $\begin{array}{c}65 \\
82 \\
425\end{array}$ & $\begin{array}{l}11.4 \\
14.3 \\
74.3\end{array}$ & $\begin{array}{c}251 \\
97 \\
24\end{array}$ & $\begin{array}{c}67.5 \\
26.1 \\
6.5\end{array}$ & $<0.0001$ \\
\hline
\end{tabular}

Table 2. The unadjusted and adjusted odds ratio and $95 \%$ confidence interval of the association between residence in wet counties and being an alcohol-related homicide victim.

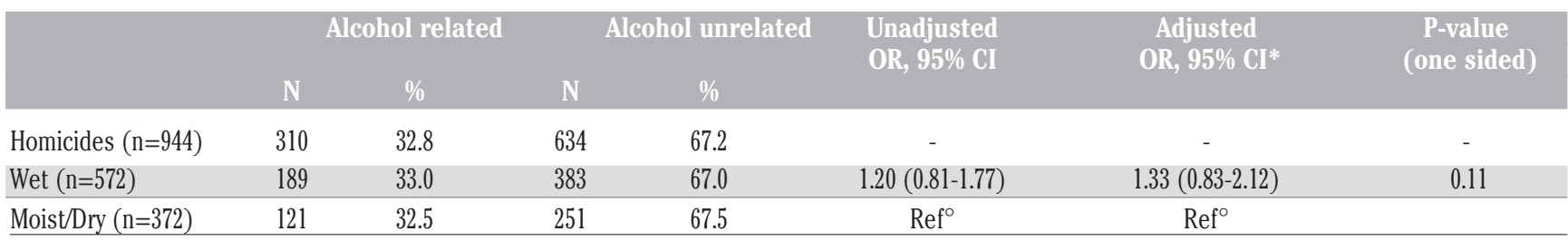

OR, odds ratio. *The final model for homicides was adjusted for education level, sex and population. The fully saturated model for homicides included age, education level, sex and population. ${ }^{\circ}$ The reference category, i.e. the group with which the first category was compared. 
ties and being an alcohol-related homicide victim. The descriptive statistics showed that $33.0 \%$ of homicide victims from wet counties were positive for alcohol post mortem compared to $32.5 \%$ of those from dry counties. In addition, residence in wet counties was associated with a statistically insignificant $20 \%$ increase in the unadjusted OR of a homicide victim having consumed alcohol $(\mathrm{OR}=1.20,95 \% \mathrm{CI}=0.81-1.77)$. Adjusting for education level sex, and population did not change the effect estimate significantly.

Homicide rates by county were spatially autocorrelated (Moran's $I=0.26$, P-value $\leq 0.0001$ ) (map not shown). The LISA map in Figure 1 shows a large high- rate cluster among several rural counties adjacent to, or within, Kentucky's Appalachian region - three wet, five dry, and one moist county. Other areas of concern included rural Cumberland County (dry) in southern Kentucky and urban Louisville-Jefferson County (wet). There were no homicides reported in six (5\%) of Kentucky's 120 counties: Boone, Campbell, Carroll, Green, Laurel and Trimble, which was due to excluding cases because they lacked values regarding one or more of the confounding factors.

In contrast, there was only very slight, and statistically insignificant, spatial autocorrelation among alcohol-related homicide rates (Moran's $I=0.1$, P-value=0.07), (map not shown). Furthermore, the LISA map in Figure 2 shows only a few scattered high-rate clusters - two in a wet, two in a moist and one in a dry county.

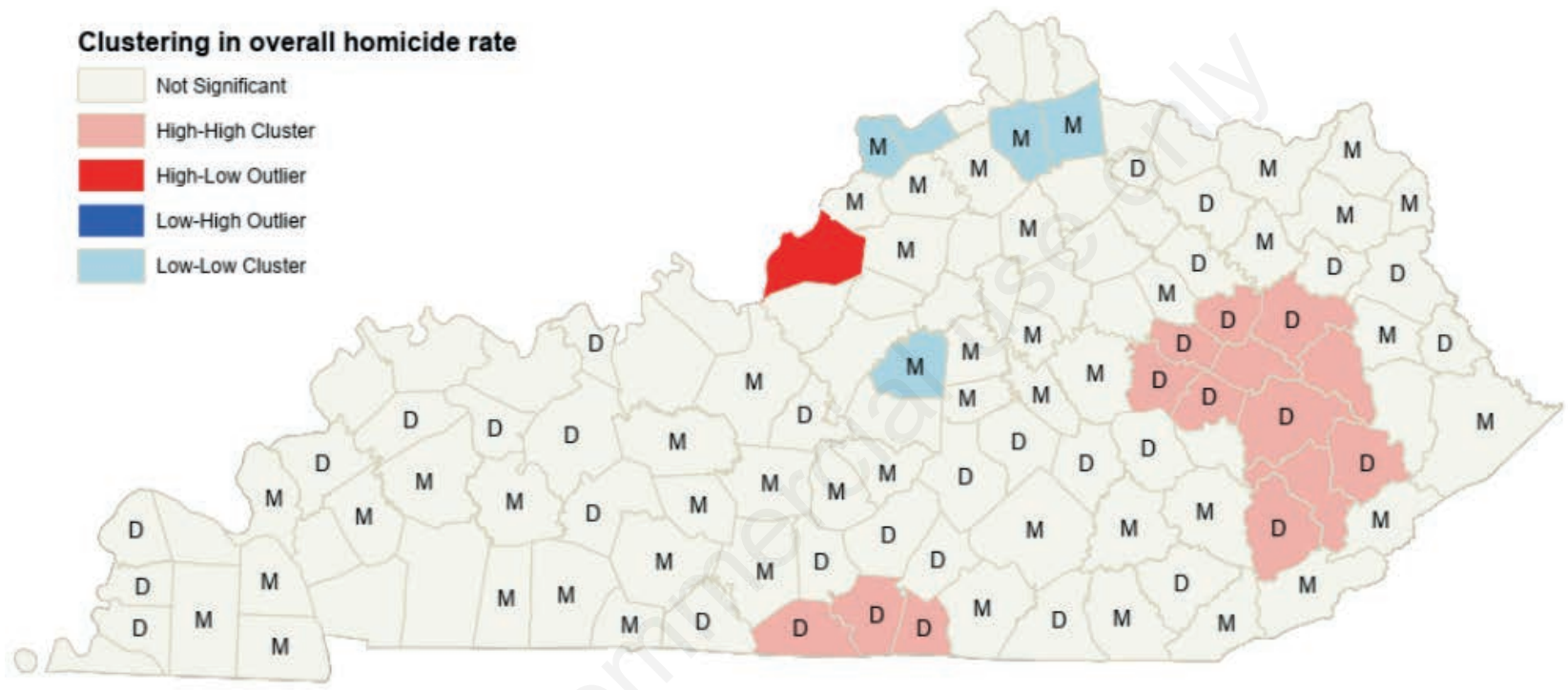

Figure 1. Cluster and outlier analysis of homicide rates in Kentucky, 2005-2012.

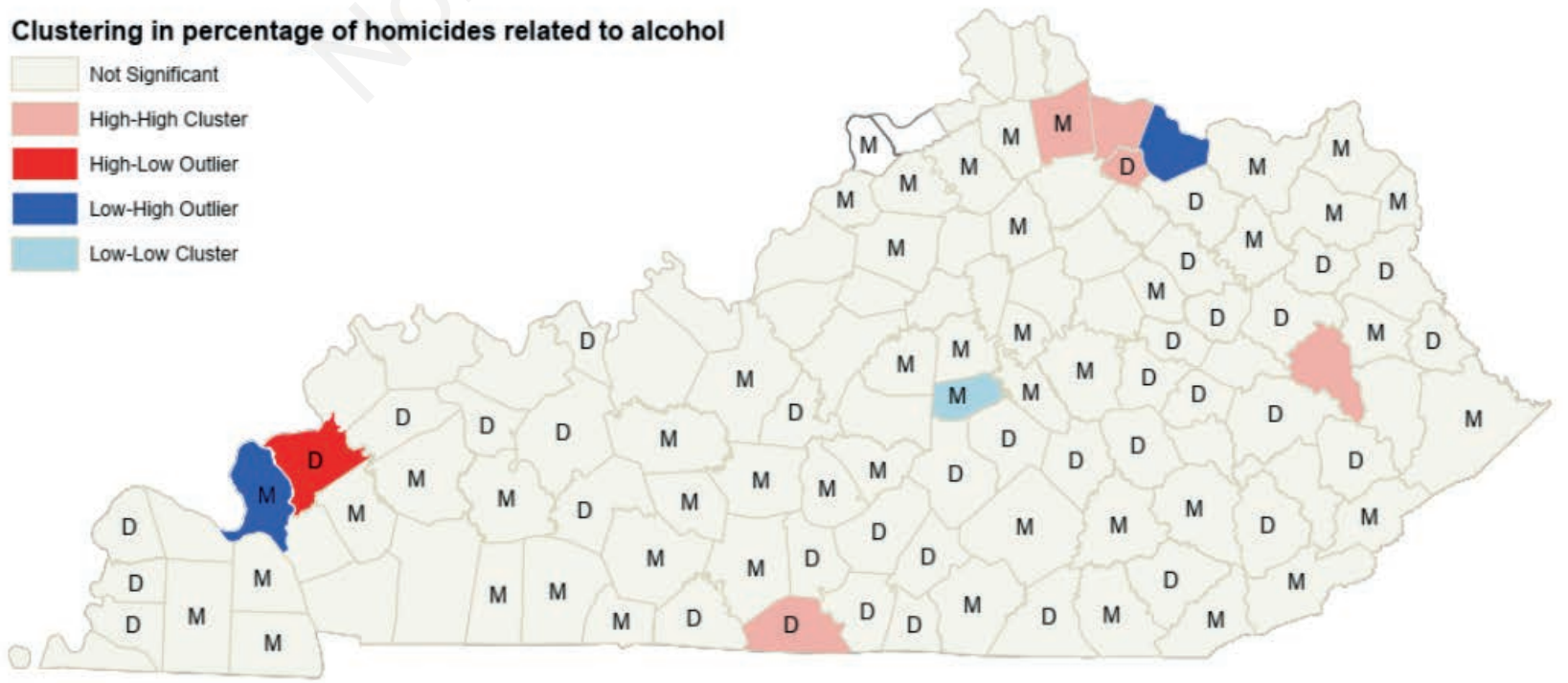

Figure 2. Cluster and outlier analysis of alcohol-related homicide rates in Kentucky, 2005-2012. 


\section{Discussion and Conclusions}

The aim of the current study was to find out if there are increased odds for a resident in a wet county of becoming a homicide victim after having consumed alcohol, which makes this investigation the first to focus on the association between local alcohol sales status and alcohol-related homicides. Our research adds to the current literature by studying the association between residency in wet counties and becoming an alcohol-related homicide victim, while adjusting for individual factors and counties using multilevel modelling (Gmel et al, 2016). We used spatial statistics to examine spatial autocorrelation of alcohol-related homicide rates in Kentucky (Gmel et al., 2016) with the underlying hypothesis that living in wet areas where alcohol sales are allowed on and off premises may create an environment that encourages drinking and therefore promotes associated harmful activities (Livingston et al., 2007).

In this study, alcohol was present in $32.8 \%$ of all homicide victims investigated. The percentage of homicide victims who were found to reside in wet counties and were positive for alcohol $(33.0 \%)$ was similar to the percentage of homicide victims residing in moist/dry counties and who were also positive for alcohol $(32.5 \%)$. These percentages were similar to those in other studies on the role of alcohol in homicide victimization (Kuhns et al., 2011; Chermack et al., 2012). We also found a 33\% increase in the odds of being an alcohol-related homicide victim among residents of wet counties compared to residents of moist/dry counties $(\mathrm{aOR}=1.33,95 \% \mathrm{CI}=0.83-2.12)$ after adjusting for education level, sex and population; however, the association was not statistically significant. We also found that the odds of homicide victims having consumed alcohol increased with education from the $8^{\text {th }}$ grade.

Results from spatial analysis did not provide evidence of spatial autocorrelation among county-level rates of alcohol-related homicides. However, results from the spatial analysis were not adjusted for potential confounders, such as sex and educational level. In addition, the spatial analysis was not adjusted for countylevel factors, such as unemployment and economic status. Furthermore, the spatial analysis showed clustering of high homicide rates in the Appalachian region as well as clustering of alcohol-related homicides in counties in this region and nearby counties, which consist of a mixture of wet, moist, and dry counties. Again, results from the spatial analysis were not adjusted for confounders. However, these findings combined might indicate that residents of wet counties might be exposed to the negative social effects of alcohol reflected in high homicide rates. In addition, clusters in dry counties may suggest that the alcohol restriction policy is not achieving what it was meant to achieve. In fact, it may suggest that banning of alcohol may have resulted in other legal or illegal ways of obtaining alcohol and therefore resulting in increased odds of alcohol-related victimization. Alternatively, it would be relatively easy for people in dry counties to obtain alcohol by travelling to neighbouring wet counties, which could explain the low level of statistical significance.

There are no prior studies of the homicide victims investigated here with which to compare our findings of the association between alcohol sales and being an alcohol-related homicide. However, results from our study add to the existing literature of aggregate alcohol consumption and homicide rates (Mann et al., 2006; Pridemore and Chamlin, 2006; Norstrom et al., 2010; Ramstedt, 2011; Wolf et al., 2014), alcohol sales and homicides rates (Norstrom, 2011a; 2011b), of density of alcohol outlets and youth homicides (Parker et al., 2011) and of extended hours of sales and consumption of alcohol with increasing homicide rates (Sanchez et al., 2011). Alcohol promotes violent behaviour through increasing the tendency for misunderstandings in personal interactions (Weizmann-Henelius et al., 2012; Anderson et al., 2014). Alcohol availability may create an environment that cultivates alcohol consumption and violence (Zinkiewicz et al., 2016).

There is a global consensus that alcohol consumption is a major public health problem leading to preventable morbidity and mortality (Rehm et al., 2007; Weizmann-Henelius et al., 2012). Estimates predicted that every 0.35 litre increase in the per capita total alcohol consumption for the period 1994-2002, should result in an approximately a 9\% increase in alcohol-related mortality, $1 \%$ increase in accidents, $4 \%$ increase in homicide and 3\% increase in assaults (Andreasson et al., 2006). A recent study in New Zealand that used geographically weighted regression to examine the relationship between alcohol outlet density and violence, as measured by police activity, found that each additional bar or nightclub that opened was associated with nearly 5.3 additional violent events per year, and one additional licensed club was associated with 0.8 additional violent events per year (Cameron et al., 2015). Results from other studies report comparable findings (McKinney et al., 2009; Anderson et al., 2014; Jennings et al., 2014; Hobday et al., 2015).

Spatial analysis in our study showed clustering of homicides in the Appalachian region suggesting the need for violence prevention programs that focus not only on alcohol, but also in context with other homicides risk factors in this region related to economic, geographic and unique cultural considerations.

Findings from this study could inform social agencies, research institutes, law enforcement, violence surveillance systems, the media and public health programs to plan prevention programs to reduce homicides in general and alcohol-related homicides in particular. Agencies that might include our findings in curriculum development and outreach activities include, but are not limited to, the Alcohol Policy Information System, the National Institute on Alcohol Abuse and Alcoholism and the Kentucky Department for Alcoholic Beverage Control. There is a need for better collaboration between policy makers, advocates, researchers, law enforcement and public health professionals to create planned multifaceted interventions (based on ecological and community level models) aimed at reducing alcohol-related events in communities (DiClemente et al., 2009). Evidence from the previous publications, and the current study, suggests that alcohol consumption policy prevention measures need to go beyond the individual intervention level and reach the community level as alcohol misuse and abuse is complex and therefore requires multifaceted interventions (Allamani, 2012). Interventions that aim to enhance the socioeconomic status of deprived communities include reduced access to firearms; increased police presence or surveillance in neighbourhoods with high rates of violent activities; control of drug use and trade activities; better access to, and availability of, counselling for couples and families; and reduced access to drugs and alcohol. The public also needs also to be educated about times and places of strong criminal activities. Most importantly, there is a need to improve the socioeconomic status of the Appalachian communities by increasing access to education and providing job opportunities.

This study has several strengths. To our knowledge, it is the first study of the association between residence sale status and being an alcohol-related homicide victim in Kentucky, while its 
use of multilevel modelling permitted to adjust for county- as well as individual-level confounders, such as education level and gender. The multilevel approach overcomes the ecologic fallacy that is a major limitation of prior studies. Furthermore, the use of spatial analysis, albeit unadjusted, helped to identify the situation of homicide clusters, which necessitates further investigation into those areas to identify possible prevention strategies being sensitive to regional differences (i.e. the Appalachian area).

This study has also several limitations, e.g., approximately $48 \%$ of all violent deaths lacked data with regard to either residence alcohol sale status, blood alcohol content or other variables which made it necessary to exclude them from the study. This may have resulted in a non-differential bias possibly reducing estimates towards the null. Secondly, although we assumed that the restriction of alcohol in dry counties might have led to illegal alcohol consumption among decedents, there was no information about the type of alcohol consumed to validate this assumption. Thirdly, residual confounding might exist in the spatial analyses because they were not adjusted for individual level confounders, such as gender and educational level, nor county level confounders, such as unemployment rate, gun sales and economic growth. Fourthly, wet/moist/dry status might have changed in some counties during the study period, which might have led to non-differential misclassification of the counties and underestimated the measure of the association. That is, the measurement error in the dependent variable would increase the standard errors on the regression coefficient, leading to potential Type II errors (failing to reject the null when it should be rejected), which could be another explanation for the insignificant findings. Lastly, another important limitation of the KVDRS data is that the answer No to the questions in the Coroner Investigation Reporting form does not necessarily mean that this information is negative; rather, it could mean that something is not known because the information is extracted from the decedent's relative, who may or may not have accurate information about the decedent. Furthermore, there was no specific variable describing why blood samples were not tested for alcohol. It would have been useful to know why those decedents were not tested. It is possible they were not tested because there was clear evidence at the death scene that these decedents were consuming alcohol, or perhaps because the decedent's body was decomposed which made testing impossible.

We recommend a comparison study of homicide survivors to determine the effects of alcohol on the lethality of violence. In addition, we emphasize the need for accurate data collection at the incident scene to minimize data loss. Furthermore, we recommend a multifaceted approach, rather than just focusing on alcohol prohibition, for the prevention of alcohol-related homicides.

\section{References}

Allamani A, 2012. Alcohol consumption policies and the prevention of alcohol consumption-related problems: needs, duties, and responsibilities. Subst Use Misuse 47:1252-9.

Anderson DM, Crost B, Rees DI, 2014. Wet laws, drinking establishments, and violent crime. In: IZA, ed. IZA Discussion Paper 8718. Available from: ftp.iza.org/dp8718.pdf

Andreasson S, Holder HD, Norstrom T, Osterberg E, Rossow I, 2006. Estimates of harm associated with changes in Swedish alcohol policy: results from past and present estimates. Addiction 101:1096-105.
Appalachian Regional Commission, 2015. Counties in Appalachia - Appalachian Regional Commission. Available from: http://www.arc.gov/counties. Accessed: May 21, 2015.

Asbridge M, Weerasinghe S, 2009. Homicide in Chicago from 1890 to 1930: prohibition and its impact on alcohol- and nonalcohol-related homicides. Addiction 104:355-64.

Branas CC, Richmond TS, Ten Have TR, Wiebe DJ, 2011. Acute alcohol consumption, alcohol outlets, and gun suicide. Subst Use Misuse 46:1592-603.

Cameron MP, Cochrane W, Gordon C, Livingston M, 2015. Alcohol outlet density and violence: A geographically weighted regression approach. Drug Alcohol Rev 36:280-8.

Centers for Disease Control and Prevention (CDC), 2014. N. C. f. I. P. a. C., Division of Violence Prevention. Featured topic: World Health Organization's (WHO) report on preventing suicide. Available from: http://www.cdc.gov/violenceprevention/ suicide/who-report.html Accessed: May 20, 2015.

Chermack ST, Bohnert AS, Price AM, Austin K, Ilgen MA, 2012. Substance use disorders and homicide death in veterans. J Stud Alcohol Drugs 73:10-4.

Darke S, 2010. The toxicology of homicide offenders and victims: A review. Drug Alcohol Rev 29:202-15.

Department of Alcoholic Beverage Control, 2015. KY alcoholic beverage control Wet-Dry-moist territories. Available from: http://abc.ky.gov/Licensing/Wet\%20Dry\%20List.pdf Accessed: May 20, 2015.

DiClimente RJ, Crosby RA, Kegler MC, 2009. Emerging theories in health promotion practice and research. 2nd ed. JosseyBass, San Francisco, CA, USA.

Duailibi S, Ponicki W, Grube J, Pinsky I, Laranjeira R, Raw M, 2007. The effect of restricting opening hours on alcohol-related violence. Am J Public Health 97:2276-80.

Giesbrecht N, Huguet N, Ogden L, Kaplan MS, McFarland BH, Caetano R, Conner KR, Nolte KB, 2015. Acute alcohol use among suicide decedents in 14 US states: impacts of offpremise and on-premise alcohol outlet density. Addiction 110:300-7.

Gmel G, Holmes J, Studer J, 2016. Are alcohol outlet densities strongly associated with alcohol-related outcomes? A critical review of recent evidence. Drug Alcohol Rev 35:40-54.

Grucza RA, Hipp PR, Norberg KE, Rundell L, Evanoff A, Cavazos-Rehg P, Bierut LJ, 2012. The legacy of minimum legal drinking age law changes: long-term effects on suicide and homicide deaths among women. Alcohol Clin Exp Res $36: 377-84$.

Heaton P, 2012. Sunday liquor laws and crime. J Public Econ 96:42-52.

Hobday M, Chikritzhs T, Liang W, Meuleners L, 2015. The effect of alcohol outlets, sales and trading hours on alcohol-related injuries presenting at emergency departments in Perth, Australia, from 2002 to 2010. Addiction 110:1901-9.

Jennings JM, Milam AJ, Greiner A, Furr-Holden CD, Curriero FC, Thornton RJ, 2014. Neighborhood alcohol outlets and the association with violent crime in one mid-Atlantic City: the implications for zoning policy. J Urban Health 91:62-71.

Kaplan MS, Huguet N, McFarland BH, Caetano R, Conner KR, Giesbrecht N, Nolte KB, 2014. Use of alcohol before suicide in the United States. Ann Epidemiol 24:588-92.e1-2.

Khaleel HA, Brown SV, Christian WJ, Fleming S, 2016. Alcohol sale status and suicide in Kentucky, 2005-2012. J Alcohol Drug Depend 4:240. 
Kuhns JB, Maguire ER, 2012. Drug and alcohol use by homicide victims in Trinidad and Tobago, 2001-2007. Forensic Sci Med Pathol 8:243-51.

Kuhns JB, Wilson DB, Clodfelter TA, Maguire ER, Ainsworth SA, 2011. A meta-analysis of alcohol toxicology study findings among homicide victims. Addiction 106:62-72.

Livingston M, Chikritzhs T, Room R, 2007. Changing the density of alcohol outlets to reduce alcohol-related problems. Drug Alcohol Rev 26:557-66.

Logan JE, Smith SG, Stevens MR, 2011. Homicides - United States, 1999-2007. MMWR 60:67-70.

Malaga H, Gonzalez M, Huaco C, Sotelo M, 2012. The relation between the number of hours that authorize the sale of alcoholic beverages and violence. Health Promot Perspect 2:60-71.

Mann RE, Zalcman RF, Smart RG, Rush BR, Suurvali H, 2006. Alcohol consumption, alcoholics anonymous membership, and homicide mortality rates in Ontario 1968 to 1991 . Alcohol Clin Exp Res 30:1743-51.

McKinney CM, Caetano R, Harris TR, Ebama MS, 2009. Alcohol availability and intimate partner violence among US couples. Alcohol Clin Exp Res 33:169-76.

Middleton JC, Hahn RA, Kuzara JL, Elder R, Brewer R, Chattopadhyay S, Fielding J, Naimi TS, Toomey T, Lawrence B, Task Force on Communituy Preventive Services, 2010. Effectiveness of policies maintaining or restricting days of alcohol sales on excessive alcohol consumption and related harms. Am J Prev Med 39:575-89.

Norstrom T, 2011a. Alcohol and homicide in the United States: is the link dependent on wetness? Drug Alcohol Rev 30:458-65.

Norstrom T, 2011b. The role of alcohol in the Russian mortality crisis. Addiction 106:1957-65.

Norstrom T, Miller T, Holder H, Osterberg E, Ramstedt M, Rossow I, Stockwell T, 2010. Potential consequences of replacing a retail alcohol monopoly with a private licence system: results from Sweden. Addiction 105:2113-9.

Parker RN, Williams KR, McCaffree KJ, Acensio EK, Browne A, Strom KJ, Barrick K, 2011. Alcohol availability and youth homicide in the 91 largest US cities, 1984-2006. Drug Alcohol Rev 30:505-14.

Pridemore WA, Chamlin MB, 2006. A time-series analysis of the impact of heavy drinking on homicide and suicide mortality in Russia, 1956-2002. Addiction 101:1719-29.

Ramstedt M, 2011. Population drinking and homicide in Australia: a time series analysis of the period 1950-2003. Drug Alcohol Rev 30:466-72.

Ray JG, Moineddin R, Bell CM, Thiruchelvam D, Creatore MI, Gozdyra P, Cusimano M, Redelmeier DA, 2008. Alcohol sales and risk of serious assault. PLoS Med 5:1-7.

Rehm J, Taylor B, Roerecke M, Patra J, 2007. Alcohol consumption and alcohol-attributable burden of disease in Switzerland, 2002. Int J Public Health 52:383-92.

Sanchez AI, Villaveces A, Krafty RT, Park T, Weiss HB, Fabio A, Puyana JC, Gutiérrez MI, 2011. Policies for alcohol restriction and their association with interpersonal violence: a time-series analysis of homicides in Cali, Colombia. Int $\mathrm{J}$ Epidemiol 40:1037-46.

SAS/STAT, 2014. The GLIMMIX Procedure. Available from: https://support.sas.com/documentation/onlinedoc/stat/132/gli mmix.pdf

Walsh S, Wang Z, Stromberg AJ, Bush H, 2009. Violent deaths in Kentucky 2005-2010: A statewide statistical summary of homicides, suicides and unintentional firearm fatalities. Kentucky Violent Death Reporting System. Available from: https://www.cdc.gov/violenceprevention/datasources/nvdrs/in dex.html?CDC_AA_refVal=https $\% 3 \mathrm{~A} \% 2 \mathrm{~F} \% 2 \mathrm{Fwww} . \mathrm{cdc}$.gov $\% 2$ Fviolenceprevention $\% 2$ Fnvdrs $\% 2$ Findex.html

Weizmann-Henelius G, Matti Gronroos L, Putkonen H, Eronen M, Lindberg N, Hakkanen-Nyholm H, 2012. Gender-specific risk factors for intimate partner homicide - a nationwide registerbased study. J Interpers Violence 27:1519-39.

Wolf A, Gray R, Fazel S, 2014. Violence as a public health problem: an ecological study of 169 countries. Soc Sci Med 104:220-7.

Zeoli AM, Webster DW, 2010. Effects of domestic violence policies, alcohol taxes and police staffing levels on intimate partner homicide in large US cities. Inj Prev 16:90-5.

Zinkiewicz L, Curtis A, Meurer H, Miller P, 2016. Demographic risk factors for alcohol-related aggression in and around licensed venues. Alcohol Alcohol 51:196-200. 